FERRAZ, Deise Brião; COSTA, Eder Dion de Paula. O acesso dos trabalhadores à justiça através da Substituição Processual por Sindicatos. Revista Eletrônica Direito e Política, Programa de PósGraduação Stricto Sensu em Ciência Jurídica da UNIVALI, Itajaí, v.12, n.3, 30 quadrimestre de 2017. Disponível em: www.univali.br/direitoepolitica - ISSN 1980-7791

\title{
O ACESSO DOS TRABALHADORES À JUSTIÇA ATRAVÉS DA SUBSTITUIÇÃO PROCESSUAL POR SINDICATOS
}

THE JUSTICE ACCESS OF WORKERS THROUGH PROCEDURAL SUBSTITUTION BY SYNDICATES

Deise Brião Ferraz ${ }^{1}$

Eder Dion de Paula Costa²

SUMÁRIO: Introdução; 10 estado está enfermo; 2 O acesso à justiça: "não basta o acesso, a ordem jurídica tem que ser justa"; Considerações finais; Referências das fontes citadas

\section{RESUMO}

A Constituição Federal de 1988, em seu art. 80, III, previu a Legitimidade Extraordinária Sindical que veio a instrumentalizar o acesso das Associações Civis à Justiça, entre elas os Sindicatos, para que postulem direito não próprio através da figura da Substituição Processual. Nestes termos, buscar-se-á através destes apontamentos o aprofundamento da tutela coletiva de direitos exercida pelos Sindicatos, partindo-se da premissa de que esse arquétipo processual promove o acesso dos trabalhadores à Justiça e promove a concretização desse Direito Fundamental, além de trazer segurança jurídica e celeridade processual.

PALAVRAS-CHAVE: Acesso à justiça; Direitos Fundamentais; Direito coletivo; Legitimidade extraordinária; Substituição processual

\begin{abstract}
The Federal Constitution of 1988, in its article $8^{\circ}$, III, provided the Extraordinary Legitimacy this Syndicates that came to instrument the access of Civil Associations to Justice, among them the Syndicates, so that they postpone their own right through the figure of the Procedural Substitution. In these terms, it will be sought through these notes to deepen the collective tutelage of rights exercised by the Syndicates, starting from the premise that this procedural archetype promotes worker's access to justice and promotes the realization of this Fundamental Social Law, in addition to Legal certainty and procedural speed.
\end{abstract}

KEYWORDS: Access to Justice; Fundamental Rights; Collective Rights; Extraordinary Legitimacy; Procedural Substitution

\footnotetext{
1 Mestranda em Direito e Justiça Social pela Universidade Federal do Rio Grande - FURG. Bolsista CAPES/DS. E-mail: deisebferraz@gmail.com.

2 Professor Associado na Universidade Federal do Rio Grande - FURG. Doutor em Direito pela Universidade Federal do Paraná - UFPR. E-mail: ederdion@gmail.com.
} 
FERRAZ, Deise Brião; COSTA, Eder Dion de Paula. O acesso dos trabalhadores à justiça através da Substituição Processual por Sindicatos. Revista Eletrônica Direito e Política, Programa de PósGraduação Stricto Sensu em Ciência Jurídica da UNIVALI, Itajaí, v.12, n.3, 30 quadrimestre de 2017. Disponível em: www.univali.br/direitoepolitica - ISSN 1980-7791

\section{INTRODUÇÃO}

A tutela coletiva de direitos, analisada nestes apontamentos sob o enfoque da Substituição Processual por Sindicatos pode ser percebida como uma forma de instrumentalizar o Acesso dos trabalhadores à Justiça, partindo-se da premissa norteadora de que o referido arquétipo processual promove esse Direito Fundamental. A fim de corroborar essa ideia, serão apontados os diversos obstáculos que tem impedido o acesso obreiro à Justiça e as alternativas apresentadas pela Substituição Processual para concentrar demandas, incentivar o associativismo, despersonificar os conflitos e suportar o ônus econômico quando comparado com demandas ajuizadas individualmente pelos trabalhadores.

Essa análise parte da Constituição Federal de 1988 que, no capítulo destinado aos Direitos e Garantias Fundamentais, sublinhou, no inciso XXXV, do art 50, que "A lei não excluirá da apreciação do Poder Judiciário, lesão ou ameaça a direito", bem como insculpiu no inciso LXXVIII do mesmo artigo que o processo deve ter duração razoável. Entretanto, para que a ameaça ou lesão a direito seja levada à conhecimento, foi instituída a necessidade de legitimidade daquele que busca a tutela jurisdicional. Com isso, considera-se a legitimidade para a causa como indispensável para que o direito de ação seja exercido. Ao lado da Legitimidade Ordinária, encontra-se a Extraordinária, inscrita no art. $8^{\circ}$, III, CF, em que o legislador possibilitou às associações e entidades constituídas há pelo menos um ano, que tenham por escopo a proteção do bem que seja objeto do processo, a postulação de direitos não próprios. Tal Legitimidade Extraordinária, instrumentalizada pela figura da substituição processual, encontra respaldo na Lei de Ação Civil Pública (LACP - Lei no 7.347/85) bem como no Código de Defesa do Consumidor (CDC - Lei no 9.078/90), com passagens pelo Código de Processo Civil, de aplicação subsidiária.

A Substituição Processual no âmbito do Direito do Trabalho tutela os Direitos Individuais Homogêneos, que são aqueles decorrentes de matéria fática e jurídica comum que englobam trabalhadores que compartilham situação uniforme, proveniente de causa comum, atingidos em sua esfera jurídica 
FERRAZ, Deise Brião; COSTA, Eder Dion de Paula. O acesso dos trabalhadores à justiça através da Substituição Processual por Sindicatos. Revista Eletrônica Direito e Política, Programa de PósGraduação Stricto Sensu em Ciência Jurídica da UNIVALI, Itajaí, v.12, n.3, 30 quadrimestre de 2017. Disponível em: www.univali.br/direitoepolitica - ISSN 1980-7791

patrimonial e moral. Ao reunir um grupo de trabalhadores que compartilha uma mesma realidade fática e são afetados pelos mesmos problemas, tem-se um empoderamento desses trabalhadores e um encorajamento para que suas demandas cheguem ao Judiciário. Adianta-se, que o ingresso de um processo único que contempla considerável número de envolvidos, instiga a economia e a celeridade processual - o que pode ser considerado de grande serventia em meio a um Judiciário sobrecarregado. Ademais, a Substituição atua como instrumento de política judiciária, à mediada que promove a segurança jurídica em pronunciamentos uniformes para situações idênticas que não serão julgadas por juízos diversos e firma posicionamentos jurisprudenciais.

Há de ser exaltada a importância desse instrumento de tutela coletiva, sobretudo, quanto à despersonificação dos conflitos trabalhistas já que, entre as maiores relutâncias dos trabalhadores em ingressar judicialmente referem-se ao temor que sentem em relação à represália dos patrões e o marco de seus nomes junto à lista dos empregados "incontratáveis" que carregam o estigma de já terem ingressado na Justiça contra seus empregadores. Logo, a coletivização da tutela dos direitos individuais homogêneos solucionaria, assim, o fato de que os trabalhadores se dispõem a propor reclamatórias trabalhistas somente quando finda a relação de emprego, pois, a experiência vivenciada na realidade trabalhista tem mostrado que o ajuizamento de uma demanda, durante o contrato de trabalho, implica na perda do emprego. Esta afirmação vem a corroborar a ideia de que muitas lesões ou ameaças a Direito ficam, sim, excluídas da apreciação do Poder Judiciária e que emerge a necessidade de se buscar formar alternativas para solucionar a questão.

\section{O ESTADO ESTÁ ENFERMO}

Em crítica que se mostra contemporânea, Sarlet ${ }^{3}$ aduz que o Estado Social de Direito está enfermo e que este contexto afeta os Estados e a Sociedade. A crise pode ser evidenciada em cada corte do governo para enxugar custos na previdência e nas prestações sociais e pode ser visualizada pelo enfraquecimento

${ }^{3}$ SARLET, Ingo Wolfgang. Os direitos fundamentais sociais na Constituição de 1988. In: Revista Diálogo Jurídico, Salvador, Ano I, Vol. I, n.1, 2001, p.4. 
FERRAZ, Deise Brião; COSTA, Eder Dion de Paula. O acesso dos trabalhadores à justiça através da Substituição Processual por Sindicatos. Revista Eletrônica Direito e Política, Programa de PósGraduação Stricto Sensu em Ciência Jurídica da UNIVALI, Itajaí, v.12, n.3, 30 quadrimestre de 2017. Disponível em: www.univali.br/direitoepolitica - ISSN 1980-7791

do Estado que tem cada vez menos capacidade de garantir que os cidadãos possam fruir de seus Direitos Fundamentais. Santos ${ }^{4}$ ressalta a crise e queda do contrato social, contrato este que se baseia no bem comum e na vontade geral e vem se mostrando incapaz de sobreviver em meio ao que denomina de "apartheid", polarizado por alguns eixos econômicos, sociais, políticos e trata-se de um processo de fragmentação da sociedade.

Santos $^{5}$ denomina e classifica formas de "fascismo social" enfrentadas diariamente pelos cidadãos, tais como o fascismo da insegurança que se funda sobre o sentimento de insegurança da população e dos grupos sociais vulnerabilizados pela precariedade de emprego ou por acidentes ou acontecimentos desestabilizadores. Nesta modalidade as pessoas encontram-se tão temerosas de seu futuro presente que alargam sua tolerância, de forma a aceitar situações que Ihe são onerosas em troca de um pouco mais de segurança ou um pouco menos de insegurança. Outra forma de fascismo social é o fascismo financeiro. Este, apesar de cruel amplamente disseminado através do controle de mercados financeiros que resultam das decisões de investidores individuais ou institucionais espalhados pelo mundo inteiro, que nada tem em comum para além do desejo de maximizar os seus ativos.

Essa realidade funda um novo contratualismo, com termos abismalmente injustos e com predomínio dos processos de exclusão. Estes processos de exclusão se traduzem em duas formas assumidas: o pós-contratualismo e o précontratualismo. Aquele, o pós-contratualismo nas palavras de Santos $^{6}$ "[...] é o processo por meio do qual grupos e interesses sociais até aqui incluídos no contrato social se vêem excluídos deste sem qualquer perspectiva de regresso." A partir daí "Os direitos de cidadania, até agora considerados inalienáveis, são confiscados e, sem eles, os excluídos passam de cidadãos a servos." enquanto que o pré-contratualismo "[...] consiste em impedir o acesso à cidadania a

4 SANTOS, Boaventura de Sousa. Poderá o Direito ser emancipatório? Revista Crítica de Ciências Sociais. Coimbra, n. 65, p. 3-76, maio, 2003, p.13.

5 SANTOS, Boaventura de Sousa. Poderá o Direito ser emancipatório? p.20

${ }^{6}$ SANTOS, Boaventura de Sousa. Poderá o Direito ser emancipatório? p. 18 
FERRAZ, Deise Brião; COSTA, Eder Dion de Paula. O acesso dos trabalhadores à justiça através da Substituição Processual por Sindicatos. Revista Eletrônica Direito e Política, Programa de PósGraduação Stricto Sensu em Ciência Jurídica da UNIVALI, Itajaí, v.12, n.3, 30 quadrimestre de 2017. Disponível em: www.univali.br/direitoepolitica - ISSN 1980-7791

grupos que anteriormente se consideravam candidatos à cidadania e tinham razoáveis expectativas de a ela aceder."

A soma destes fatores gera uma permanente angústia nos trabalhadores quanto a quantidade e continuidade do trabalho, à continuidade do mercado, ao mesmo tempo que angustia os desempregados e aqueles que nem mesmo encontram-se aptos a procurar emprego, os jovens que não conseguem adentrar o mercado de trabalho, os deficientes, os agricultores, aos trabalhadores migrantes e indocumentados que nem mesmo existem oficialmente. Boaventura7 acrescenta, ainda, que a desigualdade entre as partes é tão abismal que a parte mais fraca trabalhador, aceita as condições impostas pela parte mais forte, sejam elas de qualquer ordem, atendendo aos requisitos de um projeto neoliberal de transformação do contrato de trabalho em um contrato de Direito Civil como qualquer outro. Neste sentido, cabe a reflexão de Bobbio ${ }^{8}$, quando se refere ao problema enfrentado no momento atual, indicando que o problema que temos não é filosófico, é jurídico e em uma última análise, é político. Não se precisa quantificar ou identificar os direitos, ou mesmo fundamentá-los, mas, sim, descobrir qual o modo mais seguro para lhes garantir sem que sejam frequentemente violados.

Nesse diapasão, atendendo os ensinamentos de Warat $^{9}$ ao dizer que as práticas jurídicas devem aproximar-se dos excluídos e dos esquecidos do mundo - e os trabalhadores estão sendo colocados neste lugar de exclusão e, considerando que se entende a substituição processual como uma maneira inclusão, nestes tempos em que, parafraseando Warat ${ }^{10}$, o Estado de Direito é apenas um "holograma".

7 SANTOS, Boaventura de Sousa. Poderá o Direito ser emancipatório? p. 19.

${ }^{8}$ BOBBIO, Norberto. A era dos direitos. Traduzido por Carlos Nelson Coutinho. Nova Ed. Rio de Janeiro: Elsevier, 2004. 7a reimpressão, p. 17.

9 WARAT, Luis Alberto. A Rua grita Dionísio! Direitos Humanos da alteridade, surrealismo e cartografia. Tradução e organização: Vivian Alves de Assis, Júlio Cesar Marcellino Jr. e Alexandre Morais da Rosa. Rio de Janeiro: Lumen Juris, 2010, p.3.

10 WARAT, Luis Alberto. A Rua grita Dionísio! Direitos Humanos da alteridade, surrealismo e cartografia, p.15. 
FERRAZ, Deise Brião; COSTA, Eder Dion de Paula. O acesso dos trabalhadores à justiça através da Substituição Processual por Sindicatos. Revista Eletrônica Direito e Política, Programa de PósGraduação Stricto Sensu em Ciência Jurídica da UNIVALI, Itajaí, v.12, n.3, 30 quadrimestre de 2017. Disponível em: www.univali.br/direitoepolitica - ISSN 1980-7791

\section{O ACESSO À JUSTIÇA: "NÃO BASTA O ACESSO, A ORDEM JURÍDICA TEM QUE SER JUSTA"}

A problemática do acesso à Justiça deve transbordar os cínicos limites do acesso aos órgãos judiciais, pois, não é mera questão de possibilitar o acesso à Justiça, mas, sim, na sábia lição de Watanabe ${ }^{11}$, trata-se de viabilizar o acesso à ordem jurídica justa. Para Capelletti ${ }^{12}$ "O acesso à justiça pode, portanto, ser encarado como o requisito fundamental $[. .$.$] de um sistema jurídico moderno e igualitário$ que pretenda garantir, e não apenas proclamar os direitos de todos." Watanabe ${ }^{13}$ vai ao extremo e sinaliza que, ao invés de aplicar esse direito injusto, melhor seria dificultar o acesso à Justiça a fim de evitar o cometimento de dupla injustiça. Capelletti ${ }^{14}$ lembra que a expressão "acesso à Justiça" é de difícil definição, mas serve para determinar duas finalidades básicas do sistema jurídico - o sistema pelo qual as pessoas podem reivindicar seus direitos e/ou resolver seus litígios sob a égide do Estado que, primeiro deve ser realmente acessível a todos e deve produzir resultados que sejam individual e socialmente justos. Esse conceito de acesso à justiça tem sofrido uma transformação importante, lembrando que nos estados liberais burgueses dos séculos dezoito e dezenove, os procedimentos para solução dos litígios refletiam a filosofia essencialmente individualista dos direitos. À medida que as sociedades cresceram, as ações e relacionamentos assumiram, cada vez mais, caráter mais coletivo que individual, por isso, nas sociedades modernas a tendência é de reconhecimento crescente dos direitos e deveres sociais, inclusive das associações, como é o caso dos Sindicatos.

\footnotetext{
11 WATANABE, Kazuo. Acesso à Justiça e Sociedade Moderna. In: Caderno de Administração da Justiça - Planejamento Estratégico 2009. Porto Alegre: TRF - 4a Região, 2009, p. 128.

12 CAPPELleTtI, Mauro; GARTH, Bryant: Acesso à Justiça. Traduzido por Ellen Gracie Northfleet. Porto Alegre: Fabris Editor, 1988 p.5.

13 WATANABE, Kazuo. Acesso à Justiça e Sociedade Moderna.

14 CAPPELLETTI, Mauro; GARTH, Bryant: Acesso à Justiça. p.3
} 
FERRAZ, Deise Brião; COSTA, Eder Dion de Paula. O acesso dos trabalhadores à justiça através da Substituição Processual por Sindicatos. Revista Eletrônica Direito e Política, Programa de PósGraduação Stricto Sensu em Ciência Jurídica da UNIVALI, Itajaí, v.12, n.3, 30 quadrimestre de 2017. Disponível em: www.univali.br/direitoepolitica - ISSN 1980-7791

Cappelletti ${ }^{15}$ traz ainda outras contribuições ao lembrar as vantagens e desvantagens de determinados litigantes com base em pesquisas sociológicas que mostram que 1) pessoas ou organizações com recursos financeiros consideráveis apresentam uma notável vantagem ao propor ou defender demandas, pois podem pagar por isso e suportar as morosidades do litígio. Ocorre que, quando essa vantagem está concentrada apenas na mão de uma das partes do litígio torna-se uma arma poderosa visto que uma das partes pode defender seus argumentos com mais eficiência e, considerando que o julgamento depende da obtenção e apresentação de provas e discussão da causa pelas partes, a justiça mostra-se inacessível para muitos, como nos casos que envolvem relações de trabalho com um empregado versus o empregador em relação de poder abismalmente desigual; 2) A "capacidade jurídica pessoal" que leva em conta as barreiras que precisam ser transpassadas para que um direito possa ser reivindicado no sistema judiciário. Essa capacidade depende proporcionalmente dos recursos financeiros, educação, meio e status social e propriamente a questão de reconhecer a existência de um direito que pode ser exigido na justiça; 3) A falta de conhecimento a respeito da maneira de ajuizamento de uma demanda. Ou seja, há uma desinformação que paralisa. Essa desinformação se relaciona com a disposição psicológica para ingressar com demandas judiciais. 4) Há uma declarada desconfiança nos advogados, principalmente nas classes menos favorecidas. 5) Somado a isso, os procedimentos complexos, formalismo, ambientes que intimidam com figuras que oprimem (juízes e advogados) fazem com que o litigante se sinta, conforme Cappelletti16 "[...] um prisioneiro num mundo estranho".

Sem que seja necessário ir além, é possível perceber quais empecilhos se apresentam ao trabalhador quando do momento de ingresso com uma demanda judicial: a demora decorrente da sobrecarga do aparelho judiciário, decisões não uniformes que geram insegurança jurídica, além da insegurança decorrente quanto à continuidade do contrato de trabalho. Logo, já é simples pensar na

\footnotetext{
${ }^{15}$ CAPPELLETTI, Mauro; GARTH, Bryant: Acesso à Justiça. p.8

${ }^{16}$ CAPPELLETTI, Mauro; GARTH, Bryant: Acesso à Justiça. p. 9
} 
FERRAZ, Deise Brião; COSTA, Eder Dion de Paula. O acesso dos trabalhadores à justiça através da Substituição Processual por Sindicatos. Revista Eletrônica Direito e Política, Programa de PósGraduação Stricto Sensu em Ciência Jurídica da UNIVALI, Itajaí, v.12, n.3, 30 quadrimestre de 2017. Disponível em: www.univali.br/direitoepolitica - ISSN 1980-7791

ação coletiva como uma possível solução para estes problemas de acesso à justiça. Embora o acesso à justiça venha sendo aceito como um direito básico, sua efetividade não tem alcançado o plano desejado, pois isto só poderia se dar através da paridade de armas que diz respeito à garantia de que a condução da demanda depende apenas de questões jurídicas sem qualquer relação com as diferenças estranhas ao Direito, o que considera utópico.

Ao encontro do cenário já detalhado, Mota ${ }^{17}$ aponta que o grande problema do Judiciário hoje é o de não ser de eficácia universal, o que se manifesta em três principais aspectos, quais sejam a falta de acesso da Justiça à maioria das pessoas, decisões norteadas pela vontade de manutenção do status quo, e a morosidade das decisões. Ressalta, ainda, que há um custo econômico na provocação da atividade jurisdicional que não pode ser ignorado e que os organismos de assistência judiciária gratuita não são suficientes para abarcar todas as demandas emergentes e consigna, que, com base em sua prática como juiz, teve ciência de que até o gasto com transporte é um obstáculo à ida das pessoas à Justiça.

Não bastasse o ora exposto, há razões de ordem moral como o receio das pessoas em não verem atendido seu pleito, falta de efetividade das decisões que Ihe sejam favoráveis ou mesmo a eternização de suas demandas que incentivam o afastamento entre os tutelados e o Poder Judiciário. Há um ponto de suma importância apontado por Mota ${ }^{18}$ que diz respeito ao fato de o Poder Judiciário ser integrado em grande parte por servidores provenientes da elite dominante que trabalha na perpetuação desse poder na elite e na manutenção do status quo, reforçando a subsistência do estado de exclusão de considerável parte da população.

A tutela coletiva de direitos no âmbito do Direito do Trabalho é capaz de igualar ou, pelo menos, aproximar essa igualdade necessária para que seja efetivo o

17 MOTA, Marcílio Florêncio. A Substituição Processual por Sindicatos: $O$ acesso dos Trabalhadores à Ordem Jurídica Justa. Rio de Janeiro: Lumen Juris, 2008, p. 23.

18 MOTA, Marcílio Florêncio. A Substituição Processual por Sindicatos: O acesso dos Trabalhadores à Ordem Jurídica Justa. p.24 
FERRAZ, Deise Brião; COSTA, Eder Dion de Paula. O acesso dos trabalhadores à justiça através da Substituição Processual por Sindicatos. Revista Eletrônica Direito e Política, Programa de PósGraduação Stricto Sensu em Ciência Jurídica da UNIVALI, Itajaí, v.12, n.3, 30 quadrimestre de 2017. Disponível em: www.univali.br/direitoepolitica - ISSN 1980-7791

acesso à Justiça. Pode-se visualizar essa realidade, através de elementos presentes nas demandas coletivas como a despersonificação. A despersonificação contempla em um único processo uma quantidade expressiva de pessoas, desatrelando-se da lógica do processo individual que conduz a uma situação em que diversas pessoas que sofreram a mesma lesão ou ameaça a direito ingressem individualmente em juízo com suas demandas, contribuindo para o afogamento do judiciário e a insegurança jurídica da possibilidade de soluções diferentes para lides com origem comum e, portanto, situações idênticas. Sob essa ótica, o processo coletivo por substituição processual permitiria o ajuizamento de demanda única para o julgamento de lesões de origem comum, permitindo uma decisão uniforme e mais célere - aspectos positivos para o Judiciário e para os trabalhadores envolvidos.

Há ainda de se falar na despersonalização. Esta resolve uma questão amplamente conhecida, que é a exposição do trabalhador que compõe o polo ativo da demanda ao empregador que ocupa o polo passivo da lide. Ora, tal situação é, sem dúvida alguma, grande empecilho para os trabalhadores que tem seus direitos ameaçados ou lesados, quando pensam na possibilidade de ingressar judicialmente a fim de obter um provimento jurisdicional. Isso porque há um confronto entre aquele que se encontra no lado mais frágil da relação de emprego, versus aquele que se encontra na posição de mando, detentor do meio de produção e do poder econômico. Não raramente, o ingresso do trabalhador em juízo ainda durante o curso do contrato de trabalho causa grande insegurança ao obreiro a respeito da continuidade de seu emprego, ora porque teme sofrer represálias, ora porque teme pelo próprio emprego. Além de que o conflito existente tem forma adversarial no atual modelo de processo que se tem.

Watanabe ${ }^{19}$, afirmam que quando ações individuais são ajuizadas para a tutela de um interesse que é vinculado a uma pluralidade de pessoas, elas clamam por uma solução comum e que a multiplicação de demandas individuais contribui

19 WATANABE, Kazuo. Disposições gerais. In: GRINOVER, Ada Pellegrini. et al. Código Brasileiro de Defesa do Consumidor comentado pelos autores do anteprojeto. 9a Ed. Rio de Janeiro: Forense Universitária, 2007. p. 790-873 
FERRAZ, Deise Brião; COSTA, Eder Dion de Paula. O acesso dos trabalhadores à justiça através da Substituição Processual por Sindicatos. Revista Eletrônica Direito e Política, Programa de PósGraduação Stricto Sensu em Ciência Jurídica da UNIVALI, Itajaí, v.12, n.3, 30 quadrimestre de 2017. Disponível em: www.univali.br/direitoepolitica - ISSN 1980-7791

para a sobrecarga do judiciário, criando o terreno perfeito para que casos que merecem soluções idênticas sejam julgados de forma diferente, o que incentiva a atomização de demandas que deveriam ser tratadas de maneira molecularizada.

A atomização é um conceito cunhado por Watanabe para tratar da técnica de fragmentação dos conflitos, bem como a molecularização, que se refere à aglutinação de interesses e direitos individuais homogêneos em processos coletivos. Logo, aquilo que Watanabe ${ }^{20}$ chama de molecularização de demandas, ou seja, seu tratamento coletivo opõe-se ao que ele alcunha de atomização de demandas, de forma que a experiência jurídica adota de forma massiva este último tratamento dos conflitos trabalhistas, o que sobrecarrega o Judiciário com demandas similares e repetitivas, com decisões muitas vezes distintas, apesar de as reclamatórias decorrerem de uma mesma situação fática.

Embora a Justiça do Trabalho receba informalmente o prestígio de ser aquela em que os processos tramitam com mais celeridade, não se pode olvidar o caminho que há para ser percorrido na entrega da prestação jurisdicional em tempo razoável. Isso porque o número de reclamações trabalhistas é crescente no país, não podendo gerar efeito diverso do que a sobrecarga do aparelho judiciário e, por consequência, a demora na entrega prestacional.

Conforme detalha Mota ${ }^{21}$, na década de 1980 contabilizou-se a propositura de 9.164.557 processos trabalhistas; Na década de 1990 esse número cresceu para 20.856.684; Na década de 2000, somente até 2005 o TST já contabilizava 13.550.714 processos autuados em todo país. No ano de 2015, o TST computou 2,6 milhões de ações distribuídas pelas Varas do Trabalho de todo país.

Conforme aponta o site do TST 22 em relação ao relatório "Justiça em números" do CNJ, o desempenho da Justiça do Trabalho foi o seguinte:

\footnotetext{
20 WATANABE, Kazuo. Acesso à Justiça e Sociedade Moderna.

21 MOTA, Marcílio Florêncio. A Substituição Processual por Sindicatos: O acesso dos Trabalhadores à Ordem Jurídica Justa. p. 77

22 Relatório Justiça em Números 2015 destaca produtividade e informatização da Justiça do Trabalho. Disponível em http://www.tst.jus.br/noticias/-/asset_publisher/89Dk/content/relatorio-
} 
FERRAZ, Deise Brião; COSTA, Eder Dion de Paula. O acesso dos trabalhadores à justiça através da Substituição Processual por Sindicatos. Revista Eletrônica Direito e Política, Programa de PósGraduação Stricto Sensu em Ciência Jurídica da UNIVALI, Itajaí, v.12, n.3, 30 quadrimestre de 2017. Disponível em: www.univali.br/direitoepolitica - ISSN 1980-7791

Justiça do Trabalho conseguiu, em 2014, baixar mais casos do que o número de processos recebidos durante o ano, 0 que deve resultar em redução do estoque para o final do ano. O Índice de Atendimento à Demanda (IAD), que faz a relação entre o total de processos baixados e o de casos novos, foi de 105,5\% - o maior desde 2009. Em 19 dos 24 Tribunais Regionais do Trabalho (TRTs), o índice superou o patamar de $100 \%$ em pelo menos uma das instâncias. No Tribunal Superior do Trabalho, a carga de trabalho dos magistrados subiu $11 \%$, e o número de processos julgados aumentou $13.8 \%$. A Justiça do Trabalho concentra $20 \%$ dos magistrados e $15 \%$ dos servidores do Poder Judiciário brasileiro. Durante o ano passado, cerca de 4 milhões de sentenças e decisões foram proferidas, das quais $81 \%$ no $1^{\circ}$ grau. Em média, cada magistrado baixou o equivalente a 1.238 processos, o que significa uma média de 103 casos resolvidos por mês, por magistrado. Com isso, o Índice de Produtividade de Magistrados (IPM), que avalia a produtividade do magistrado conforme 0 número de processos baixados, apresentou alta de 5,3\% no último ano e $18,3 \%$ no período de 2009 a 2014. O Índice de Produtividade dos Servidores da Área Judiciária (IPS-Jud), também registrou aumento de 5,7\%.

A partir dos dados apresentados algumas análises merecem destaque: a elevação na carga de trabalho dos magistrados em $11 \%$ e o aumento no número de processos julgados em $13.8 \%$, inevitavelmente, provocam de forma colateral a sobrecarga humana dos magistrados que recebem cada vez mais trabalho, o que se reflete também na qualidade das decisões por eles proferidas. Pode-se dimensionar a qualidade das decisões também se considerando que durante um ano cerca de 4 milhões de sentenças foram proferidas, sendo que mais de $80 \%$ foram no $1^{\circ} \mathrm{grau}$, contabilizando-se a média de 103 casos resolvidos por mês.

A divulgação dessas estatísticas pelo TST parece anunciar algum tipo de vitória ou melhoria na Justiça do Trabalho com efeitos práticos na vida dos tutelados. Entretanto, tais estatísticas quando analisadas em conjunto com todos os entraves já mencionados neste trabalho, os quais os trabalhadores estão sujeitos - lembre-se: falta de acesso ao judiciário, linguagem inacessível, falta de assistência jurídica gratuita, perseguição por partes dos empregadores, temores, em 15/06/2016. 
FERRAZ, Deise Brião; COSTA, Eder Dion de Paula. O acesso dos trabalhadores à justiça através da Substituição Processual por Sindicatos. Revista Eletrônica Direito e Política, Programa de PósGraduação Stricto Sensu em Ciência Jurídica da UNIVALI, Itajaí, v.12, n.3, 30 quadrimestre de 2017. Disponível em: www.univali.br/direitoepolitica - ISSN 1980-7791

constrangimentos, decisões disformes para situação fática de origem comum, mostram que o relatório do CNJ é um holograma, ou seja, não representa efeitos positivos práticos para os demandantes.

Mota $^{23}$ denuncia que há no âmbito do TST um problema sério quanto ao tempo de tramitação dos recursos, uma vez que os agravos de instrumento propostos contra a negativa de subida de recurso de revista no ano de 2006, por exemplo, tiveram prazo médio de julgamento de 615 dias e o recurso de revista em si teve prazo médio de 1.178 dias para julgamento. Isso tudo sem falar na crise das execuções trabalhistas tanto no que diz respeito à morosidade quanto a sua efetividade. Nessa fase do processo se esbarra em uma grande quantidade de outros processos acumulados também em fase de execução, além das tentativas (muitas vezes infrutíferas) para descobrir bens suscetíveis de execução, comunicação ineficiente entre órgãos de informação e os recursos disponíveis para interposição por parte dos litigantes que tornam essa fase ainda mais demorada quando comparada com a fase de cognição.

\section{CONSIDERAÇÕES FINAIS}

O período de redemocratização pelo qual o país passou após ser assolado por uma Ditadura Militar historicamente marcante e tirana trouxe consigo uma ânsia por cidadania. Tal ânsia foi em parte satisfeita em 1988, com a promulgação da Constituição Federal que, finalmente, firmou um compromisso vinculativo a todas as estruturas do poder de afirmação da cidadania que pode ser notada pela consubstanciação dos valores do ordenamento na dignidade da pessoa humana.

Boaventura (2003) aponta para a atualidade como um período em que os Estados democráticos coexistem com sociedades fascizantes, reproduzindo o fascismo sob outras formas. Warat (2010) denuncia que o chamado Estado de Direito é apenas um "holograma" e que a tutela constitucional dos direitos fundamentais pressupõe que os tutelados sejam cidadãos e não excluídos, pois

23 MOTA, Marcílio Florêncio. A Substituição Processual por Sindicatos: O acesso dos Trabalhadores à Ordem Jurídica Justa. p. 78 
FERRAZ, Deise Brião; COSTA, Eder Dion de Paula. O acesso dos trabalhadores à justiça através da Substituição Processual por Sindicatos. Revista Eletrônica Direito e Política, Programa de PósGraduação Stricto Sensu em Ciência Jurídica da UNIVALI, Itajaí, v.12, n.3, 30 quadrimestre de 2017. Disponível em: www.univali.br/direitoepolitica - ISSN 1980-7791

enquanto forem excluídos, nunca serão cidadãos. A fim de reverter essa exclusão, o autor reafirma a necessidade das práticas jurídicas que aproximem os excluídos.

Compreende-se, conforme já explanado neste trabalho que o caminho de aproximação dos excluídos é o acesso à justiça como forma de promover os direitos fundamentais e isso se mostra possível através da Substituição Processual pelos sindicatos. Nas lições de Cappelletti (1988), a efetividade do acesso à justiça não tem alcançado o plano desejado já que este só poderia ocorrer através de completa "igualdade de armas", o que naturalmente implica na garantia de que condução da demanda dependa apenas de questões jurídicas sem qualquer relação com as diferenças estranhas ao Direito, o que considera utópico.

Ao compreender a Substituição Processual como um instrumento de promoção dos Direitos Fundamentais não se pode ignorar que elas se tratam de uma oportunidade de se ver emergir a importância dos Sindicatos enquanto agrupamentos associativos e força de luta. As associações traduzem a importância do agrupamento de uma classe e podem, através da substituição processual, mostrar aos seus associados seu nível de comprometimento com a efetivação dos direitos, fortalecendo sua representatividade e prestígio.

Ademais, a Substituição Processual por sindicatos atua na defesa de interesses individuais homogêneos de grupos, categoria, classe de pessoas determinadas ou determináveis com direitos oriundos de circunstâncias de origem comum e pode colaborar com a harmonização de decisões judiciais que tratam dos mesmos direitos decorrentes de origem comum, evitando decisões disformes quando comparadas com pleitos individualmente intentados por trabalhadores.

Frisa-se que as associações tem mais chance de êxito na escolha de profissionais da advocacia porque podem constituir corpo de advogados especificamente designados para atender os interesses da categoria que representam de forma especializada ao passo que as instituições públicas de assistência judiciária muitas vezes são precárias e tem recursos materiais insuficientes para atender a demanda, além de não estarem presentes de forma universal atendendo todas 
FERRAZ, Deise Brião; COSTA, Eder Dion de Paula. O acesso dos trabalhadores à justiça através da Substituição Processual por Sindicatos. Revista Eletrônica Direito e Política, Programa de PósGraduação Stricto Sensu em Ciência Jurídica da UNIVALI, Itajaí, v.12, n.3, 30 quadrimestre de 2017. Disponível em: www.univali.br/direitoepolitica - ISSN 1980-7791

as regiões geográficas deste país de dimensões continentais. Nessa ótica, as associações podem suportar as despesas do processo, disponibilizando advogados especializados para os pleitos empreendidos.

Chama-se atenção também para o fato de que os trabalhadores, em geral, depois do fim do regime de estabilidade que foi substituído pelo regime do Fundo de Garantia Social (FGTS), tendem a pleitear os direitos que viram violados durante o contrato de trabalho somente depois de dispensados porque temem a represália do empregador e a dispensa. Por isso, pode-se dizer que a Justiça do Trabalho é a Justiça dos Desempregados, afinal os empregados não podem arriscar seus empregos em uma possível retaliação patronal.

Não bastasse isso, não se pode olvidar da prática bastante comum de troca de informações entre empregadores para dificultar o acesso do trabalhador demandante ao mercado de trabalho, fomentando a lista dos trabalhadores "incontratáveis", afinal, empregador algum quer ser demandado. Todo esse cenário reflete a falta de efetividade das normas trabalhistas e a perda do direito de ação, conduzindo novamente à importância da Substituição Processual na despersonalização dos conflitos.

Contempla-se na Substituição Processual sindical essa possibilidade de promover - acesso à Justiça, diminuir a sobrecarga do judiciário e, colateralmente, fomentar a celeridade processual, com decisões justas e harmonizadas, sem a oferta de riscos aos trabalhadores quanto à retaliação patronal, promovendo o associativismo e atenuando as desigualdades gritantes entre os detentores dos meios de produção e os obreiros. 
FERRAZ, Deise Brião; COSTA, Eder Dion de Paula. O acesso dos trabalhadores à justiça através da Substituição Processual por Sindicatos. Revista Eletrônica Direito e Política, Programa de PósGraduação Stricto Sensu em Ciência Jurídica da UNIVALI, Itajaí, v.12, n.3, 30 quadrimestre de 2017. Disponível em: www.univali.br/direitoepolitica - ISSN 1980-7791

\section{REFERÊNCIA DAS FONTES CITADAS}

BOBBIO, Norberto. A era dos direitos. Tradução de Carlos Nelson Coutinho. Nova Ed. Rio de Janeiro: Elsevier, 2004. 7a reimpressão.

BRASIL. Constituição (1988). Constituição da República Federativa do Brasil. Brasília, DF: Senado, 1988.

Código de Processo Civil. Brasília, DF: Senado, 2015.

do Trabalho.

Lei no 5452 de $1^{\circ}$ de maio de 1943. Aprova a Consolidação das Leis

CAPPELLETTI, Mauro; GARTH, Bryant. Acesso à Justiça. Tradução de Ellen Gracie Northfleet. Porto Alegre: Fabris Editor, 1988.

CENTRO BRASILEIRO DE ESTUDOS E PESQUISAS JUDICIAIS/ CENTRO DE PESQUISA JURÍDICA APLICADA DA ESCOLA DE DIREITO DE SÃO PAULO DA FUNDAÇÃO GETULIO VARGAS. Avaliação da prestação jurisdicional coletiva e individual a partir da judicialização da saúde. GRINOVER, Ada Pellegrini (Coord.). SICA, Ligia Paula P. Pinto (Coord.) São Paulo, 2014.

MOTA, Marcílio Florêncio. A Substituição Processual por Sindicatos: 0 acesso dos Trabalhadores à Ordem Jurídica Justa. Rio de Janeiro: Lumen Juris, 2008.

SANTOS, Boaventura de Sousa. Poderá o Direito ser emancipatório? Revista Crítica de Ciências Sociais. Coimbra, n. 65, p. 3-76, maio, 2003.

Cortez, 2007.

Para uma revolução democrática da justiça. 3a Ed. São Paulo:

SARLET, Ingo Wolfgang Os direitos fundamentais sociais na Constituição de 1988. In: Revista Diálogo Jurídico, Salvador, Ano I, Vol. I, n.1, 2001.

A eficácia do Direito Fundamental à Segurança Jurídica: dignidade da pessoa humana, direitos fundamentais e proibição de retrocesso social no direito constitucional brasileiro. In: Revista Eletrônica sobre a reforma do Estado. Salvador, n. 21, 2010.

SARLET, Ingo Wolfgang; MARINONI, Luiz Guilherme; MITIDIERO, Daniel. Curso de Direito Constitucional. São Paulo: Revista dos Tribunais, 2012.

WARAT, Luis Alberto. A Rua grita Dionísio! Hireitos humanos da alteridade, surrealismo e cartografia. Tradução e organização: Vivian Alves de Assis, Júlio Cesar Marcellino Jr. e Alexandre Morais da Rosa. Rio de Janeiro: Lumen Juris, 2010.

WATANABE, Kazuo. Acesso à Justiça e Sociedade Moderna. In: Caderno de Administração da Justiça - Planejamento Estratégico 2009. Porto Alegre: TRF 4a Região, 2009 
FERRAZ, Deise Brião; COSTA, Eder Dion de Paula. O acesso dos trabalhadores à justiça através da Substituição Processual por Sindicatos. Revista Eletrônica Direito e Política, Programa de PósGraduação Stricto Sensu em Ciência Jurídica da UNIVALI, Itajaí, v.12, n.3, 30 quadrimestre de 2017. Disponível em: www.univali.br/direitoepolitica - ISSN 1980-7791

Disposições gerais. In: GRINOVER, Ada Pellegrini. et al. Código Brasileiro de Defesa do Consumidor comentado pelos autores do anteprojeto. 9a Ed. Rio de Janeiro: Forense Universitária, 2007. p. 790-873

Submetido em: outubro de 2017

Aprovado em: novembro de 2017 